\title{
DESIGN, MODELING AND EXPERIMANTATION OF A REVERSIBLE HP-ORC PROTOTYPE
}

\author{
Olivier Dumont \\ University of liege \\ Thermodynamics and Energetics Laboratory \\ Chemin des chevreuils, 7 B49, 4000 Liege \\ Belgium \\ Olivier.dumont@ulg.ac.be
}

\author{
Sylvain Quoilin \\ University of liege \\ Thermodynamics and Energetics Laboratory \\ Chemin des chevreuils, 7 B49, 4000 Liege \\ Belgium \\ squoilin@ulg.ac.be
}

\author{
Vincent Lemort \\ University of liege \\ Thermodynamics and Energetics Laboratory \\ Chemin des chevreuils, 7 B49, 4000 Liege \\ Belgium \\ Vincent.Lemort@ulg.ac.be
}

\section{ABSTRACT}

This paper presents an innovative system comprising a heat pump connected to a solar roof and a geothermal heat exchanger. This heat pump is also able to invert its cycle and operate as an ORC. By using the whole rooftop (hereunder called "absorber") as a heat source, a large amount of heat is generated throughout the year. This heat is used in priority to cover the building annual heating needs and the surplus heat generated during the summer is utilized to generate electricity in a so-called HP/ORC module. This paper will thus focus on these two main points: designing of the prototype and results from experimentation. This paper demonstrates the feasibility of such a prototype with encouraging performance in ORC and HP modes. Experimentally, a COP of 4.2 is reached in heat pump mode and a global efficiency of 5.6 is obtained in ORC mode. Possible means of improvement and perspectives are finally described.

\section{INTRODUCTION}

Building is one of the economical sectors where solutions are available to significantly reduce energy consumption and greenhouse gases emissions (37\% of the total final energy consumption of the EU [1]). Among other, heat pumps offer promising perspectives to provide energy-efficient space and domestic hot water heating in many applications [2-4]. This paper presents an innovative system comprising a heat pump connected to a solar roof and a geothermal heat exchanger (Fig. 1). This heat pump (HP) is also able to invert its cycle and operate as an organic Rankine cycle (ORC). By using the whole rooftop (hereunder called "absorber") as a heat source, a large amount of heat is generated throughout the year. This heat is used in priority to cover the building heating needs and the surplus heat generated during the summer is utilized to generate electricity in a so-called HP/ORC module [5]. The same module can be used during winter as an efficient heat pump which radically simplifies the complexity of the total system compared to competitive products (Heat pump combined with photovoltaics for example). The main advantage of the proposed technology lies in the reversibility of scroll machines, which have proven to operate efficiently both as compressor and as expander in laboratory testing.

The paper is structured as follows. The first part presents the prototype architecture and the different operational modes. The second part deals with the modeling of the systems and the evaluation of its nominal and yearly performance in the case of Denmark (the house that will host the prototype is in Herning, Denmark). The third part details the selection of the components. The fourth part presents the experimental results and their analysis. Finally, some possible improvements are proposed. 


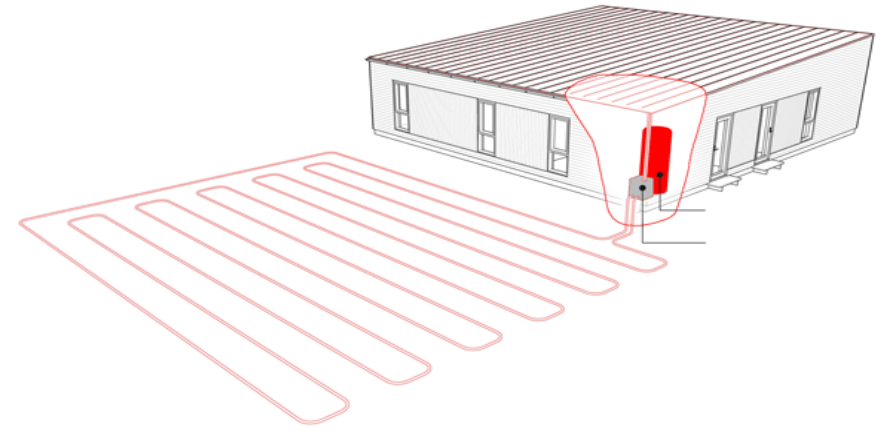

FIGURE 1 : ILLUSTRATION OF THE INNOGIE CONCEPT: THE REVERSIBLE HP-ORC MODULE IS INSERTED IN A BUILDING BETWEEN A SOLAR ROOF AND A GOETHERMAL HEAT EXCHANGER [6]

\section{DIFFERENT MODES}

\subsection{Cycle architecture}

There are two options considering the architecture of the cycle:

- The evaporator and condenser conserve their role

- Each heat exchanger plays the role of the condenser or of the evaporator depending on the operation mode

\subsubsection{Evaporator and Condenser conserve}

their role Advantages:

- Simple integration into the global system (only two 3way valves)

- Flow direction is constant, allowing easier measurements.

Drawbacks:

- Configuration with recuperator is not optimal in heat pump mode

- Heat exchangers work in very different conditions (mainly in terms of fluid density) depending on the mode. They might be oversized or undersized depending on the current mode.

3.1.2. Each heat exchanger performs as a condenser or an evaporator depending on the operation mode Advantages:

- Both heat exchangers operating in more constant conditions

- Recuperator integration is easier

- $\quad$ Less valves are needed in the refrigeration loop

Drawbacks:

- Uneasy integration into the global system.

- More valves are needed on the heat transfer loop.

3.1.3 Final architecture Since this is supposed to be a first prototype and since several uncertainties remain, the simplest and safest cycle layout is preferred to more advanced configurations. Therefore, the small comparative advantage of the cycle recuperator is not considered to be worth the additional risk linked to a supplementary component. As a consequence, no recuperator will be installed in this cycle. Although it involves more valves, the first configuration (Fig. 2) is considered as the safest because of the constant flow direction and of the liquid receiver being used in HP as well as in ORC mode.

\subsection{Direct heating}

The heat flows from the absorber to the storage/consumption via an intermediate exchanger (Fig. 2).

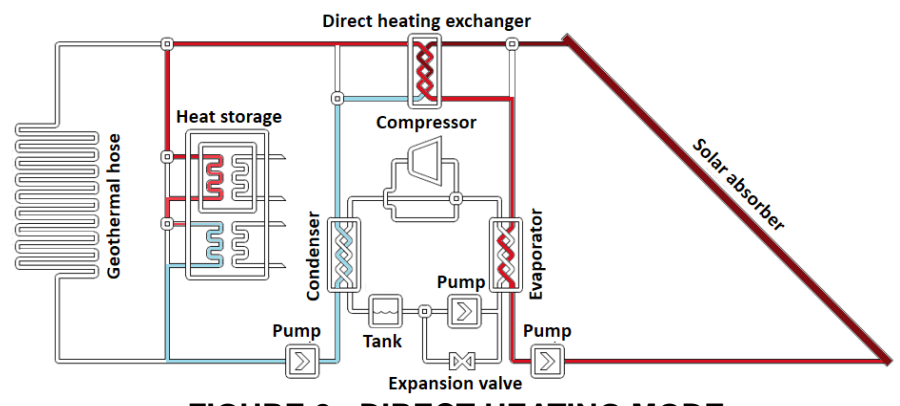

FIGURE 2 : DIRECT HEATING MODE

\subsection{ORC mode}

Whenever thermal energy is available in the absorber, the ORC is activated as long as the storage can cover the space and DHW heating requirements (Fig. 3). In the case where heating requirement are not met, the direct heating mode is activated in place of the ORC (in priority during low irradiation hours) until those requirements are satisfied. In this mode, the heat source (for the evaporator) is the solar roof and the heat sink is the geothermal heat exchanger (for the condenser). Practically, heat from the absorber is transmitted to the working fluid through the evaporator. Following that the working fluid is expanded in the volumetric machine and produce electricity. Then the refrigerant is cooled by the geothermal hose through the condenser. Finally the refrigerant goes in the pump and the cycle starts again.

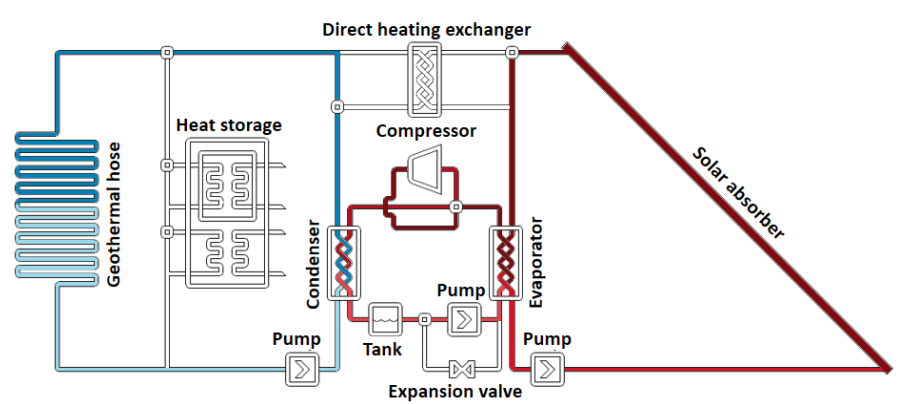

FIGURE 3 : ORC MODE

\subsection{HP mode}

During winter months, when the heating requirements exceed the heating production by direct heating, the heat pump mode is activated (Fig. 4). In this case the heat source (at the evaporator) of the cycle is the solar roof or the geothermal heat exchanger (if it is at a higher temperature) and the heat sink (at the condenser) 
is the building heating loop. Practically, heat from the absorber is transmitted to the working fluid through the evaporator. Following that the working fluid is compressed in the volumetric machine. Then the water of the storage is heated by the refrigerant through the condenser. Finally the refrigerant goes in the expansion valve and the cycle starts again.



FIGURE 4 : HEAT PUMP MODE

\section{MODELING}

\subsection{Exchanger}

The condenser and the evaporator are plate heat exchangers because of their good efficiency and compactness. They are described by a three zone's model. Heat transfer coefficients are evaluated with Thonon's correlation for single phase zones [7], with Kuo's correlation for condensation [8] and with Hsieh's correlation for evaporation [9]. The total heat transfer area is the sum of zones' areas. In the sizing model, the surface and the number of plates are calculated via an imposed pinch-point and a maximum pressure drop on refrigerant side (200 mbar) [10]. In the simulation model, the surface and the number of plates are imposed.

\subsection{Compressor}

4.2.1. Technology choice Scroll compressor is chosen mainly because of its ability to work as an expander with slight modifications and because it is an appropriate expansion device for electrical power below $10 \mathrm{~kW}$ for solar applications [11].

\subsubsection{Compressor model Manufacturer} correlations are used to model the performance of the compressor following European standard [12]. Coefficients for the three different compressors can be found on the web [13].

$$
\begin{aligned}
& \dot{W}_{c p} \\
& =C_{0}+C_{1} \cdot T_{e v}+C_{2} \cdot T_{c d}+C_{3} \cdot T_{e v}{ }^{2}+C_{4} \cdot T_{e v} T_{c d} \\
& +C_{5} \cdot T_{c d}{ }^{2}+C_{6} \cdot T_{e v}{ }^{3}+C_{7} \cdot T_{e v}{ }^{2} T_{c d}+C_{8} \cdot T_{e v} T_{c d}{ }^{2}+C_{9} \cdot T_{c d}{ }^{2} \\
& \dot{m}_{c p} \\
& =K_{0}+K_{1} \cdot T_{e v}+K_{2} \cdot T_{c d}+K_{3} \cdot T_{e v}{ }^{2}+K_{4} \cdot T_{e v} T_{c d} \\
& +K_{5} \cdot T_{c d}{ }^{2}+K_{6} \cdot T_{e v}{ }^{3}+K_{7} \cdot T_{e v}{ }^{2} T_{c d}+K_{8} \cdot T_{e v} T_{c d}{ }^{2}+K_{9} \cdot T_{c d}{ }^{2}
\end{aligned}
$$

Neglecting ambient losses, exhaust conditions are evaluated by:

$$
h_{e x, c p}=h_{s u, c p}+\frac{\dot{W}_{c p}}{\dot{m}_{c p}}
$$

Isentropic and volumetric efficiencies for the compressor are defined by Eq. 4 and Eq. 5 respectively:

$$
\begin{gathered}
\varepsilon_{c p, i s}=\frac{h_{c p, e x, i s}-h_{c p, s u}}{\dot{W}_{c o m p, e l}} \\
\varepsilon_{c p, v o l}=\frac{\dot{m}_{\text {meas }}}{\dot{m}_{t h}}
\end{gathered}
$$

4.2.3. Expander model For the expander, there is no efficiency data available. Thus, the scroll expander model is the one that has been previously proposed by [14] and validated by tests with R245fa [15]. The model requires only nine parameters (heat transfer coefficients, friction torque, leakage area and pressure drop equivalent diameter). They are scaled with the laws proposed by [16]. In this model, the evolution of the fluid through the expander is decomposed into the following steps (Fig. 5):

- $\quad$ Supply pressure drop $(\mathrm{su} \rightarrow \mathrm{su}, 1)$

- Cooling-down in the supply port of the expander (su1 $\rightarrow \mathrm{su}, 2)$

- Isentropic expansion from the supply pressure down to the adapted pressure imposed by the internal expansion volume ratio of the expander (su, $2 \rightarrow$ in);

- Expansion at constant machine volume from the adapted pressure to the exhaust pressure (in $\rightarrow$ ex,2);

- $\quad$ Mixing between suction flow and leakage flow (ex, 2 $\rightarrow$ ex, 1)

- Cooling-down or heating-up in the exhaust port (ex,1 $\rightarrow$ ex).

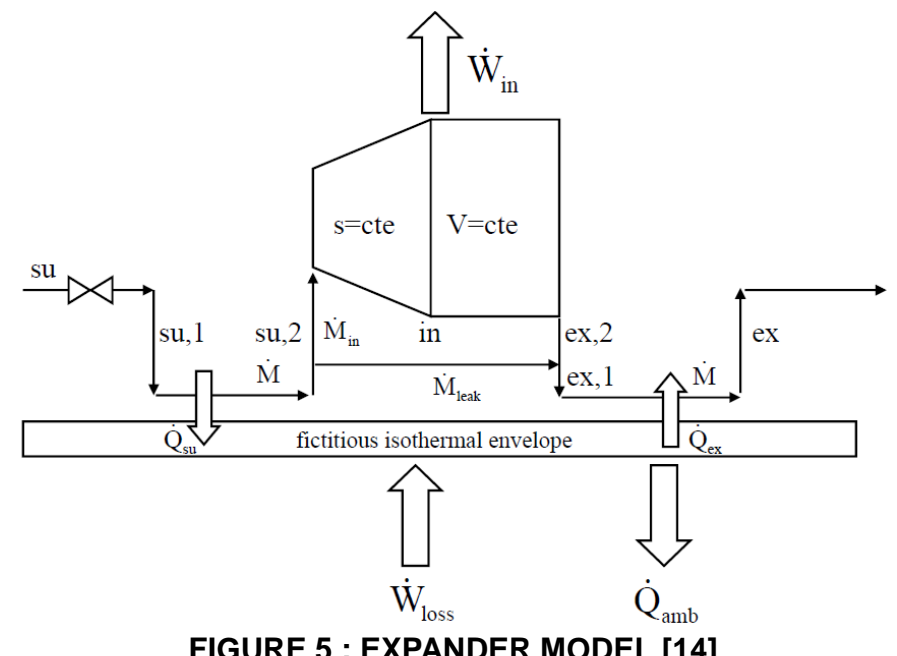

FIGURE 5 : EXPANDER MODEL [14]

Isentropic efficiency and filling factor for the expander are defined by Eq. 6 and Eq. 7 respectively: 


$$
\begin{gathered}
\varepsilon_{\text {exp }, i s}=\frac{\dot{W}_{c o m p, e l}}{h_{c p, s u}-h_{c p, e x, i s}} \\
\phi_{\text {exp }}=\frac{\dot{m}_{\text {meas }}}{\dot{m}_{t h}}
\end{gathered}
$$

\subsection{Pump}

4.3.1. Technology choice A volumetric pump is chosen because it is more adapted to low flow and high pressure ratio. Among volumetric pumps, a plunger pump is the best choice because of its:

- $\quad$ Relatively high isentropic efficiency $(\approx 50 \%)$

- Constant volumetric efficiency (even with low working fluid viscosity)

- Tightness.

4.3.2. Model In order to evaluate the specific work of the pump, isentropic effectiveness is used.

$$
\varepsilon_{i s}=\frac{\dot{m}\left(h_{e x, i s}-h_{s u}\right)}{\dot{W}_{p p}}
$$

The only parameter is $\varepsilon_{i s}$ and it is set to 0.5 .

\subsection{Solar roof}

Although the present work does not focus on the solar part of the system, a simple linear model of the absorber is implemented to determine the heat source (glycol water $-30 \%$ of glycol to avoid freezing of the fluid regarding the nominal conditions) temperature as a function of both the cycle thermal consumption and the solar irradiation. This allows yearly simulations to be performed. The efficiency is expressed as follows:

$$
\begin{gathered}
\dot{Q}_{a b s}=S_{a b s}\left(-26.2-1.22 T_{a}-1.7 \Delta T_{a b s}+0.903 I\right) \\
\eta_{a b s}=\frac{\dot{Q}_{a b s} \cdot \eta_{\text {glazing }}}{I . S_{a b s}}
\end{gathered}
$$

$\eta_{\text {glazing }}$ is the optical efficiency, i.e. transmittivity (88\%), and $\Delta T_{a b s}$ is the difference between the ambient temperature and the average heat transfer fluid temperature in the collector. It should be noted that the above correlation was established for pure water. In our case, it is used for glycol water (30\%). Therefore the actual efficiency of the absorber should be slightly reduced due to lower heat transfer coefficient and thermal capacity.

\subsection{Storage}

Thermal losses of the heat storage have to be taken into account. This has been done by assuming constant losses through the day according to the ambient temperature. These thermal losses, in [Wh/day], are defined by [17]. The volume and the storage temperature are imposed at 1000 liters and $55^{\circ} \mathrm{C}$ respectively.

$$
Q_{\text {sto }}=4,2 \cdot V_{\text {Sto }}^{0,47} \cdot\left(T_{\text {sto }}-T_{a m b}\right)
$$

\subsection{Expansion valve}

It is modelled by an adiabatic expansion valve model. The first law of thermodynamics gives Eq. 12.

$$
h_{c d, e x}=h_{e v, s u}
$$

\section{SIZING}

\subsection{Definition of the nominal conditions}

5.1.1. ORC mode Since the ORC mode is the one involving the highest heat flow through the cycle, it is the one selected for the sizing of the system components. A nominal sizing point is defined as follows:

- The evaporating temperature is set to $90^{\circ} \mathrm{C}$, which approximately corresponds to the maximum admissible pressure at the inlet of the expander ( 32 bars) with the selected fluid. The pressure at the inlet of the compressor is simply the exhaust pressure of the pump minus the pressure drop on the evaporator.

- On the cooling water side, an inlet temperature of $15^{\circ} \mathrm{C}$ and an outlet temperature of $20^{\circ} \mathrm{C}$ are assumed.

- The heat source temperature glide, i.e. the difference between the inlet and outlet glycol water temperature on the absorber, is set to $25 \mathrm{~K}$ in order to conserve a reasonable glycol water flow rate.

- The nominal pinch points are set to $5 \mathrm{~K}$ for the evaporator and $7.5 \mathrm{~K}$ for the condenser [18].

- The nominal superheating and sub cooling of the evaporator and the condenser are set to $10^{\circ} \mathrm{C}$ and $2{ }^{\circ} \mathrm{C}$ respectively.

5.1.2. HP mode For the heat pump mode, the following operating conditions are imposed:

- The evaporating temperature is selected as the equilibrium temperature when the heat pump thermal power is 8 $\mathrm{kWth}$ and when the solar insolation is $90 \mathrm{~W} / \mathrm{m}^{2}$. This is representative of winter conditions in Denmark. In December the sun provides $520 \mathrm{Wh} / \mathrm{m}^{2}$ a day [19].

- The glycol water flow rate (evaporator) is set to the value provided by the ORC mode, depending on the scroll machine power.

- The condensing temperature is fixed to $60^{\circ} \mathrm{C}$ in order to get a water temperature around $55^{\circ} \mathrm{C}$ at the inlet of the heat storage. This temperature is sufficient to cover all the needs of the house.

- For hot water production, a temperature difference of $5 \mathrm{~K}$ is assumed between the inlet and the outlet of the condenser.

- The superheating and sub-cooling of the evaporator and the condenser are set to $3^{\circ} \mathrm{C}$ and $2^{\circ} \mathrm{C}$ respectively.

The heat exchangers and the pump are sized using the nominal summer conditions. However, the size of the scroll machine (which defines the net power of the system, both in HP and ORC mode) results from a tradeoff between winter and summer conditions. This can only be optimized using yearly simulations, 
as proposed in the next section. The results presented in Tab. 1 for the nominal conditions have been obtained with the optimal expander size (swept volume $=98.04 \mathrm{~cm}^{3}$ ) and optimal fluid (R134a) resulting from yearly simulation optimization (see next section).

TABLE 1: NOMINAL CONDITIONS

\begin{tabular}{|c|c|c|}
\hline \multirow{7}{*}{ Heat pump } & $\mathrm{P}_{\mathrm{ev}}[\mathrm{bar}]$ & 5 \\
\hline & $\mathrm{P}_{\mathrm{cd}}[\mathrm{bar}]$ & 17 \\
\hline & Power consummed [W] & 3211 \\
\hline & $\dot{m}_{r}[\mathrm{~kg} / \mathrm{s}]$ & 0.1 \\
\hline & $\varepsilon_{\mathrm{comp}, \mathrm{s}}[\%]$ & 60 \\
\hline & $\eta_{\text {abs }}[\%]$ & 56 \\
\hline & $\mathrm{COP}[-]$ & 2.4 \\
\hline \multirow{7}{*}{ ORC } & $\mathrm{P}_{\mathrm{ev}}[\mathrm{bar}]$ & 33 \\
\hline & $\mathrm{P}_{\mathrm{cd}}[\mathrm{bar}]$ & 7 \\
\hline & Power produced [W] & 4733 \\
\hline & $\dot{m}_{r}[\mathrm{~kg} / \mathrm{s}]$ & 0.3 \\
\hline & $\varepsilon_{\exp , \mathrm{s}}[\%]$ & 68 \\
\hline & $\eta_{\text {abs }}[\%]$ & 55.3 \\
\hline & $\eta_{\mathrm{ORC}}[\%]$ & 6.1 \\
\hline
\end{tabular}

\subsection{Evaluation of the seasonal performance of the HP/ORC system}

In the previous section, the performance of the system has been evaluated on a nominal sizing point, allowing to select and to define the geometry of some components. However, as already mentioned, it is important to account for the performance of the system over a whole year when optimizing its design. In this section the system is simulated over a whole year with a time step of one hour by taking into account the average climatic conditions, the average building heat demand for each month of the year and the control strategy. The climate is defined by the outside temperature and by the solar irradiance for each hour of the year in Copenhagen. The control strategy is the following. The ORC mode is used as long as the heat storage can cover the heat demand. If this is not the case, the direct heating mode is activated. Finally, the HP mode is used during winter for severe climate conditions when the direct heating mode is not sufficient.

These simulations allow optimizing discrete variables such as the choice of the working fluid, the use of a recuperator, and the size of the scroll machine (available sizes are taken from the catalog of the manufacturer). The following methodology is applied:

1. For a given configuration (fluid, expander size, recuperator or not), the system performance (in terms of thermal and electrical powers) is evaluated over a wide range of evaporation/condensation temperatures, both for the ORC mode and the HP mode.

2. Performance curves are derived from these simulations as a function of the system configuration and of the temperature levels. Second order polynomial are used (error always inferior to $1 \%$ ).

3. These curves are implemented in the yearly simulation model, which optimally switches between the three operating modes depending on the weather conditions and on the heat demand for the given month.

\section{Selection of components}

\subsection{Working fluid}

In a first step, R134a has been chosen thanks to the Scroll expander operating map [11]. The goal of this section is to evaluate the performance of alternative fluids with a higher critical temperature than R134a. A fluid with a higher critical temperature also imposes a higher volume ratio to the system and thus increases the under-expansion losses. It will also result in a lower density and thus in higher equipment costs. Previous works have examined principal refrigerants appropriate for a low temperature ORC application [18]. A thorough literature review suggests the evaluation of a few typical fluids for applications similar to this unit: R123, R1234yf, R124, R134a, R152a, R600 and R600a.

Each of these fluids is described in the next section. They are compared using the yearly simulation and a multi-criteria approach [18]. This paper focuses both on the thermodynamic and on the economic optimization of a small scale ORC in waste heat recovery application). Table 2 compares each fluid in terms of electrical annual production especially. Some fluids (R245fa and R123) can be rejected mainly because of the low electrical production. Others presents a significant increase in electrical production (R124, R600, R152a and R600a) but are rejected because of environmental reasons or flammability. The chosen working fluid is thus the R134a although its relatively low performance.

TABLE 2: SELECTION OF THE WORKING FLUID

\begin{tabular}{|c|c|c|}
\hline Fluid & $\mathbf{W}_{\text {net }}[\mathbf{k W h}]$ & Inconvenient \\
\hline R124 & 5079 & Environmental reasons \\
\hline R600 & 4239 & Flammability \\
\hline R152a & 3969 & Flammability \\
\hline R600a & 3814 & Flammability \\
\hline R245fa & 3349 & Toxicity + low $\mathrm{W}_{\text {net }}$ \\
\hline R123 & 3105 & Environment reasons + low $\mathrm{W}_{\text {net }}$ \\
\hline R134a & 3496 & - \\
\hline
\end{tabular}

\subsection{Expander}

Table 3 presents results from yearly simulations with three different existing compressors with fluid R134a. There is an optimum in ORC mode. Too small of a compressor will show a maximum of electrical production not allowing to recover energy at high evaporator heat. Too large of a compressor will often be used in its low pressure ratio region where isentropic efficiency is low. It shows that the compressor with the intermediate displacement (Tab. 4) is the more appropriated in heat pump and ORC mode.

TABLE 3: SELECTION OF THE COMPRESSOR 


\begin{tabular}{|c|c|c|c|}
\hline Compressor & A & B & C \\
\hline \hline Swept volume [cm3] & 82.6 & 98.04 & 119.9 \\
\hline Volume ratio [-] & 2.8 & 2.8 & 2.8 \\
\hline ORC annual production [kWh] & 3834 & 4030 & 3910 \\
\hline HP annual consumption [kWh] & 532 & 527 & 611 \\
\hline
\end{tabular}

TABLE 4: TECHNICAL DATA OF THE COMPRESSOR

\begin{tabular}{|c|c|c|}
\hline \multirow{2}{*}{} & $\begin{array}{c}\text { Displacement (cp } \\
\text { mode) }\end{array}$ & $98.04 \mathrm{~cm}^{3}$ \\
\cline { 2 - 3 } & $\begin{array}{c}\text { Built-in volume } \\
\text { ratio }\end{array}$ & $\sim 2.8$ \\
\cline { 2 - 3 } & $\begin{array}{c}\text { Max pressure } \\
\text { Motor power at } \\
\text { max current }\end{array}$ & $32 \mathrm{bar}$ \\
\hline
\end{tabular}

\subsection{Evaporator}

The model, presented in section 5, leads to a surface of 6.94 $\mathrm{m}^{2}$ and 58 plates. Finally the exchanger from Tab. 5 is chosen following the manufacturer advices concerning the dragging of oil with the refrigerant.

\section{TABLE 5: TECHNICAL DATA OF THE EVAPORATOR}

\begin{tabular}{|l|l|l|}
\hline \multirow{4}{*}{$\rightarrow \infty$} & Number of plates & 70 \\
\cline { 2 - 3 } & Exchange area & $4.08 \mathrm{~m}^{2}$ \\
\cline { 2 - 3 } & Max. pressure & $27 \mathrm{bar}$ \\
\cline { 2 - 3 } & Max temperature & $225^{\circ} \mathrm{C}$ \\
\hline
\end{tabular}

\subsection{Condenser}

The model presented in section 5 leads to a surface of $8.43 \mathrm{~m} 2$ and 70 plates. It appears that the limitation on the sizing did not come from the pressure drop on the refrigerant size but on the water side (200 mbar). A new sizing has been made based only on the refrigerant pressure drop and it leads to a 300 mbar pressure drop on the water side. This reduces the exchanger size by half (Tab. 6) which is profitable in terms of compactness and costs. The disadvantage is that the electrical consumption of the cold loop pump is increased by 200W. This consumption represents only $4 \%$ of the electrical nominal production of the ORC.

TABLE 6: TECHNICAL DATA OF THE CONDENSER

\begin{tabular}{|l|l|l|}
\hline \multirow{2}{*}{$\rightarrow \infty$} & Number of plates & 80 \\
\cline { 2 - 3 } & Exchange area & $3.12 \mathrm{~m}^{2}$ \\
\cline { 2 - 3 } & Max. pressure & $27 \mathrm{bar}$ \\
\cline { 2 - 3 } & Max temperature & $225^{\circ} \mathrm{C}$ \\
\hline
\end{tabular}

\subsection{Pump}

The pump is chosen to achieve the $300 \mathrm{~g} / \mathrm{s}$ from 7 bar to 33 bars of the ORC nominal point (Tab. 7).

TABLE 7: TECHNICAL DATA OF THE PUMP

\begin{tabular}{|l|l|l|}
\hline \multirow{3}{*}{$(\mathrm{S}$} & Maximum flow & $15.1 \mathrm{l} / \mathrm{min}(1725 \mathrm{RPM})$ \\
\cline { 2 - 3 } & Max. pressure & $206 \mathrm{bar}$ \\
\cline { 2 - 3 } & Max temperature & $121^{\circ} \mathrm{C}$ \\
\cline { 2 - 3 } & Motor & $1.5 \mathrm{~kW}$ \\
\hline
\end{tabular}

\subsection{Expansion valve}

An electronic expansion valve is chosen because of its precise control allowing low over-heating. It is sized on the maximum nominal power in heat pump mode: $13 \mathrm{~kW}$ (Tab. 8 ).

\section{TABLE 8: TECHNICAL DATA OF THE EXPANSION VALVE}

\begin{tabular}{|l|l|l|}
\hline & Flow & Uniflow \\
\cline { 2 - 3 } & Max. pressure & $45 \mathrm{bars}$ \\
\cline { 2 - 3 } & Max temperature & $100^{\circ} \mathrm{C}$ \\
\cline { 2 - 3 } & Nominal power & $13 \mathrm{~kW}$ \\
\cline { 2 - 3 } & $\mathrm{Kv}$ & $0.21 \mathrm{~m}^{3} / \mathrm{h}$ \\
\hline
\end{tabular}

\subsection{Four ways valve}

The prototype described in this section needs to invert the supply and exhaust of the compressor. A four-way valve is used for this purpose. However, this valve is used in an unusual way: normally, it is made for reversible heat pumps (Fig. 6). The compressor discharge is then located in 1 , and the compressor suction is in 3 . The four-way valve is then able to invert the condenser and the evaporator ( 2 and 4 ). It therefore allows the production of heat and refrigeration with the same heat pump. In the case of the HP-ORC unit, its role is to switch from the HP to the ORC mode. The decision was made to always use the condenser with the exit number 2 and the evaporator with the pipe number 4 . The cycle inversion is initiated by a small solenoid pilot valve which controls the movement of a slider. The slider then changes the direction of the refrigerant. In the ORC mode, the compressor is started with the solenoid coil energized to place the piston chamber in its right position: it moves to the right. After that, the compressor is stopped and then the ORC cycle can be started.

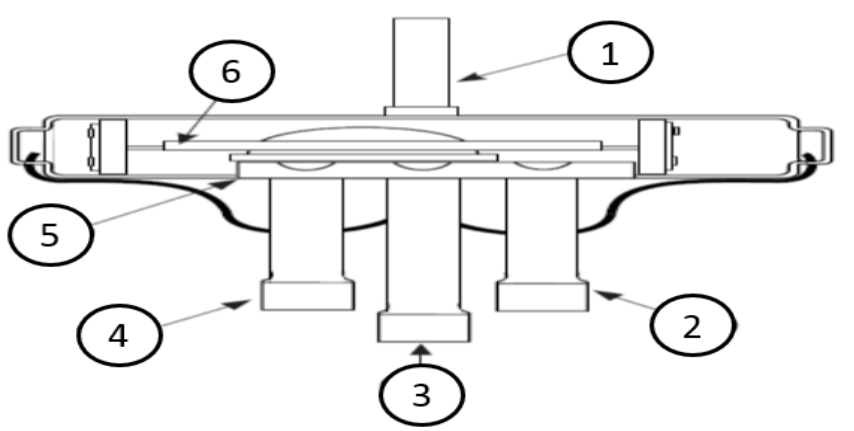

FIGURE 6: SIMPLIFIED SCHEME OF THE FOUR WAY VALVE [20]

\section{EXPERIMENTAL RESULTS}

\subsection{Experimental setup}

An experimental study was carried out on the ORC-HP prototype with R134a. A schematic representation of the test bench is given in Fig. 7. The heat source (red) consists of an electrical oil boiler. The condenser is cooled (light blue loop) by tap water (temperature ranging from $10^{\circ} \mathrm{C}$ to $20^{\circ} \mathrm{C}$ ). An oil loop (black) is installed but it is never utilized during the presented tests because lubrication is ensure by sufficient refrigerant speed. 


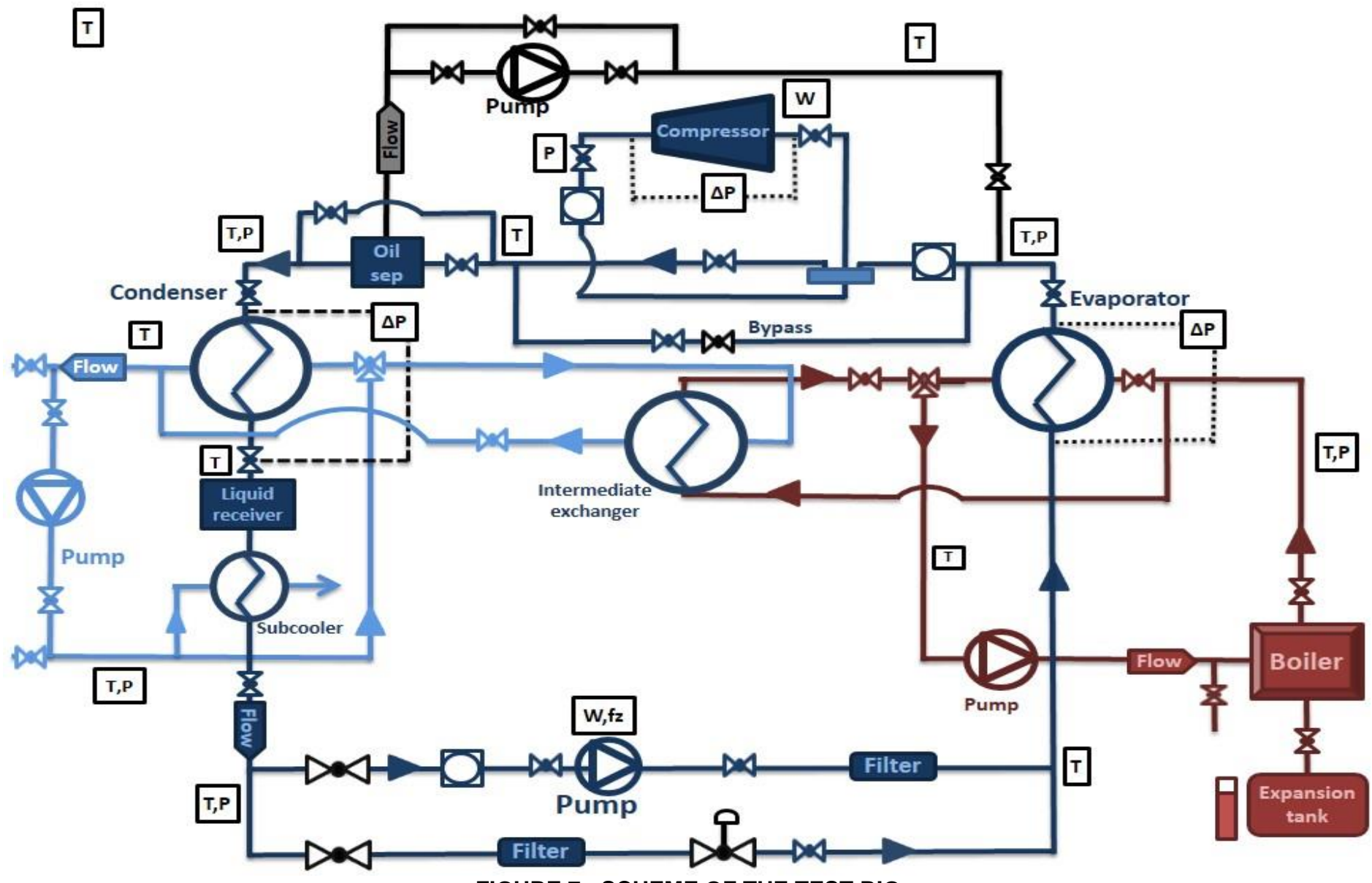

FIGURE 7 : SCHEME OF THE TEST RIG

\subsection{Nominal experimental point in ORC and HP mode}

Table 9 presents the results from first experiments. It shows the feasibility of the reversible HP/ORC unit with encouraging results in both modes. The obtained results are slightly lower than what expected in the design phase. This is explained by low efficiency of the compressor (Fig. 8), high pressure drop (up to 4 bar) on the four way valve, non-thermally insulated pipes and additional sub-cooling needed for the non-cavitation of the pump in ORC mode. Improvement section explains how to enhance this performance.

TABLE 9: EXPERIMENTAL RESULTS

\begin{tabular}{|c||c|c|}
\hline & HP (theoretical) & ORC (theoretical) \\
\hline \hline $\mathrm{P}_{\text {comp,el }}[\mathrm{kW}]$ & $3.8(4)$ & $3.7(4.7)$ \\
\hline $\mathrm{Q}_{\mathrm{ev}}[\mathrm{kW}]$ & $12.3(13)$ & $63(62)$ \\
\hline $\mathrm{Q}_{\mathrm{cd}}[\mathrm{kW}]$ & $14(17)$ & $57(56)$ \\
\hline $\mathrm{P}_{\text {pump,el }}[\mathrm{W}]$ & - & $1068(1252)$ \\
\hline$\varepsilon_{\mathrm{comp} / \text { exp,is }}[-]$ & $0.56(0.6)$ & $0.55(0.68)$ \\
\hline $\mathrm{T}_{\mathrm{ev}}\left[{ }^{\circ} \mathrm{C}\right]$ & $21.3(15)$ & $88(90)$ \\
\hline $\mathrm{T}_{\mathrm{cd}}\left[{ }^{\circ} \mathrm{C}\right]$ & $61.2(60)$ & $26(27)$ \\
\hline $\mathrm{COP} / \eta[-]$ & $4.21(4.25)$ & $4.1 \%(6.1 \%)$ \\
\hline
\end{tabular}

\subsection{Heat pump}

Figure 9 shows the volumetric and the isentropic efficiencies of the compressor for different pressure ratios. These efficiencies show classical trends: volumetric efficiency is quite constant, decreasing slightly with the pressure ratio (more internal leakages) and isentropic efficiency raises rapidly up to its maximum value at the optimum pressure ratio (around 3) and then decreasing slowly for higher pressure ratios. These efficiencies are slightly lower than what could be expected for such a compressor [16] mainly due to the fact that the design is not optimized to work in both compressor and expander. An uncertainty propagation gives errors lower than $3.5 \%$. 


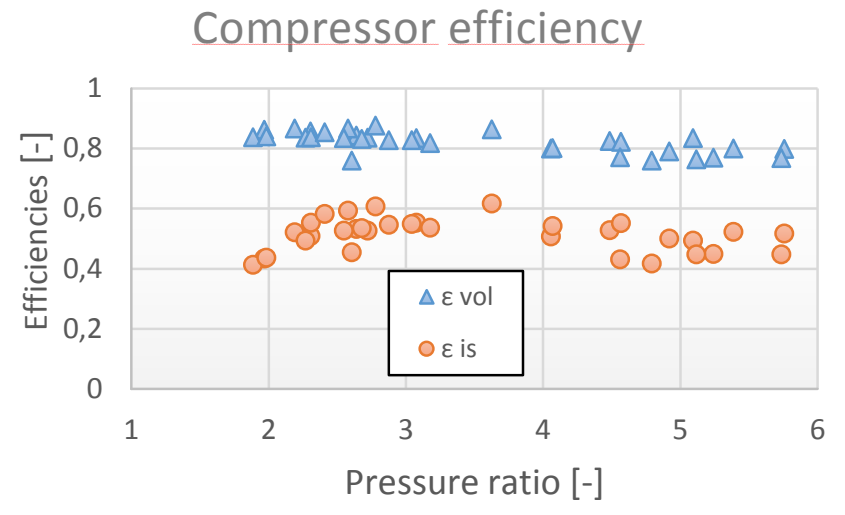

FIGURE 8 : COMPRESSOR EFFICIENCY.

Figure 9 presents the COP of the heat pump against the temperature lift $\left(\mathrm{T}_{\mathrm{cd}}-\mathrm{T}_{\mathrm{ev}}\right)$. The trend is the one expected [21].

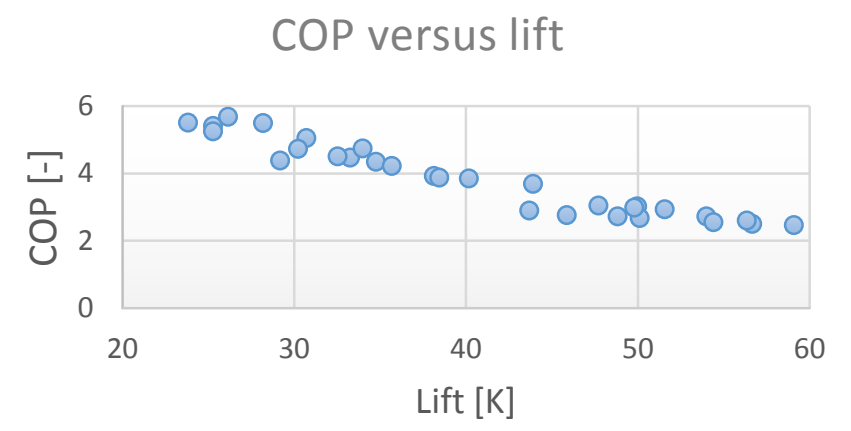

FIGURE 9 : COEFFICIENT OF PERFORMANCE VERSUS TEMPERATURE LIFT

\subsection{ORC}

Figures 10 and 11 present the evolution of the expander efficiency with the pressure ratios and the evolution of the global efficiency of the ORC with the temperature lift $\left(\mathrm{T}_{\mathrm{ev}}-\mathrm{T}_{\mathrm{cd}}\right)$. Just like the heat pump, the trends are as expected but the efficiency is slightly lower than literature [11, 14-16]. An uncertainty propagation gives errors lower than $3.5 \%$.

\section{Expander efficiency}

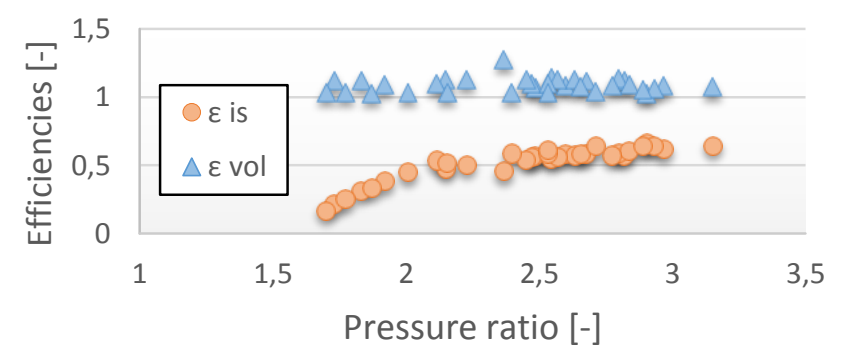

FIGURE 5 : EXPANDER EFFICIENCY.



FIGURE 61: GLOBAL EFFICIENCY VERSUS TEMPERATURE LIFT

\section{POSSIBLE IMPROVEMENTS}

\subsection{Expander}

8.2.1. Expander effectiveness The expander is originally a hermetic refrigeration compressor. As a consequence, it was not optimized for the working conditions imposed in ORC mode and presents a lower maximal effectiveness $(55 \%)$ compared to the compressor mode effectiveness (that could reach values of $75 \%$ [14]). The compressor would have a lower efficiency in heat pump mode but this mode is use only three months ( 9 months for the ORC mode). This is partly due to a too low internal built-in volume ratio of 2.8 , while the external volume ratio imposed by the cycle is 5.2 on the nominal point. Designing or selecting an expander with a higher internal volume ratio would decrease the underexpansion losses and increase the efficiency.

8.2.2. Expander maximum pressure With the considered scroll machine, the maximum pressure is set to 32 bar. This is more than enough for heat pump operation but remains too low for the ORC operating under high solar irradiation. In the yearly simulation, the maximum pressure was reached during 252 hours (out of 1653 running hours, i.e. $15.25 \%$ of the time), reducing the output power during this time period. Two solutions can be considered: selecting a working fluid with a higher critical temperature (and thus lower evaporation pressure), such as R245fa, or modifying the design of the scroll expander to increase its robustness. It should however be noted that selecting another working fluid would also increase the volume ratio imposed to the expander and thus increase the under-expansion losses.

8.2.3. Expander speed control In the simulations presented above, the only degree of freedom to control the cycle was the pump speed (i.e. the refrigerant flow rate). This allows to impose the target superheating at the expander inlet. However the evaporation pressure cannot be controlled and is fluctuating depending on the working conditions. This also involves that the average heat transfer fluid temperature in the absorber cannot be controlled. It is well known in concentrating solar power that an 
optimum heat transfer fluid temperature exists, resulting of a tradeoff between absorber efficiency and cycle efficiency. In the above simulations, this optimum was no reached, resulting in a non-optimum overall efficiency for the solar ORC system. In order to control the evaporation temperature, a second degree of freedom is needed on the cycle, namely the expander speed. This speed can be controlled by means of an inverter, controlling the frequency of the asynchronous machine integrated in the hermetic scroll expander.

\subsection{Pump}

The measured pump isentropic efficiency is never above $50 \%$ (Figure 12). This corresponds to a standard diaphragm pump, usually used in small-scale ORCs. This effectiveness being quite low, it seems reasonable to assume that an optimized pump would reach an effectiveness of about $75 \%$. For the nominal sizing point in ORC mode, this improvement would increase the net output power by $9.12 \%$ (i.e. from $4733 \mathrm{~W}$ up to $5165 \mathrm{~W}$ ).

\subsection{Four Ways valve}

As mentioned above, this valve presents huge pressure drops (up to 4 bars at maximum flow rate). It is therefore necessary to use a valve that presents a bigger section.

\section{CONCLUSION}

This study proposes an innovative reversible domestic heat pump/ORC system, allowing for both heat and electricity production depending on the weather conditions. The proposed system is based on an experimental study carried out at the Thermodynamics Laboratory of the University of Liège and demonstrating the reversibility of scroll machines. This study furthermore allowed modeling those machines with realistic efficiency curves based on laboratory measurements.

A model of the system has been developed to assess the power consumption/generation of the prototype over different operating points. A second model has then taken profit of these simulation results to evaluate the system performance over one year and to optimize its design in terms of component sizing, working fluid and architecture.

First simulations of the HP/ORC system, with the components optimally sized, indicate that, in ORC mode, the electrical energy produced over one year reaches $4030 \mathrm{kWh}$ and the monthly efficiency of the cycle varies between $4.3 \%$ and $6.4 \%$. The monthly COP of the heat pump varies from 2.6 to 3.3 , for a yearly electrical energy consumption of $527.3 \mathrm{kWh}$. The direct heating mode provides $62.3 \mathrm{kWh}$ of heat throughout the year.

The second phase of the project consists in the practical experimentation of the system. A prototype has been built, tested and confirms the feasibility of the system. A COP of 4.2 is reached in heat pump mode and a global efficiency of 5.6 is obtained in ORC mode. Possible improvements are finally presented for a new version of the prototype.
The perspectives are the following:

- Install and monitor the prototype in the house

- Validate a steady state model of each component and of the global system

- Evaluation of the performance on yearly simulation based on these experimental validation

\section{NOMENCLATURE}

10.1. Capital letters

$\begin{array}{cc}I & \text { Irradiation }\left[\mathrm{W} / \mathrm{m}^{2}\right] \\ \boldsymbol{P} & \text { Pressure }[\mathrm{Bar}] \\ \dot{\boldsymbol{Q}} & \text { Heat flux }[\mathrm{W}] \\ T & \text { Temperature }\left[{ }^{\circ} \mathrm{C}\right] \\ V & \text { Volume }\left[\mathrm{m}^{3}\right] \\ W & \text { Energy }[\mathrm{J}] \\ \dot{\boldsymbol{W}} & \text { Power }[\mathrm{W}]\end{array}$

10.2. Lowercase letters

$\begin{array}{cc}h & \text { Enthalpy }[J /(\mathrm{kg} . \mathrm{K})] \\ \dot{\boldsymbol{m}} & \text { Flow rate }[\mathrm{kg} / \mathrm{s}]\end{array}$

10.3. Greek symbols

$\begin{array}{cc}\varepsilon & \text { Effectiveness [-] } \\ \phi & \text { Filling factor [-] } \\ \eta & \text { Efficiency [-] }\end{array}$

\subsection{Subscripts}

$\begin{array}{cc}a b s & \text { Absorber } \\ a & \text { Ambient } \\ c d & \text { Condenser } \\ c p & \text { Compressor } \\ e l & \text { Electrical } \\ e v & \text { Evaporator } \\ e x & \text { Exhaust } \\ \text { in } & \text { Internal } \\ \text { is } & \text { Isentropic } \\ p p & \text { Pump } \\ \text { meas } & \text { Measured } \\ \text { sto } & \text { Storage } \\ \text { su } & \text { Supply } \\ \text { vol } & \text { Volumetric } \\ \text { th } & \text { theoretical }\end{array}$

\section{REFERENCES}

[1] Pérez-Lombard, L., Ortiz, J., Pout, C., 2008, "A review on buildings energy consumption information," Energy and building, 40, pp. 394-398.

[2] Hepbasli, A. and Kalinci, Y., 2009, "A review of heat pump water heating systems," Renewable and Sustainable Energy review, 13, pp. 1211-1229. 
[3] Georges, A., Gendebien, S., Bertagnolio, S. and Lemort, V., 2013, "Modeling and simulation of the domestic energy use in Belgium following a bottom-up approach," Proceedings of the CLIMA 2013 11th REHVA World Congress \& 8th International Conference on IAQVEC, Prague.

[4] Georges, A., Gendebien, S., Dechesne, B., Bertagnolio, S. and Lemort, V., 2013, "Impact of the integration of various heating technologies on the energy load profiles on the belgian residential building stock," 8th International Renewable Energy Storage Conference and Exhibition, berlin.

[5] Quoilin, S., Dumont,O. and Lemort V., 2013, "Design, Modeling and Performance Optimisation of a Reversible HP-ORC Prototype," proc. 2nd International Seminar on ORC Power Systems, Rotterdam.

[6] Innogie ApS, http://www.innogie.dk.

[7] Thonon B., 1995, "Recent research and developments in plate heat exchangers," Fuel and Energy Abstracts, 36(5), pp. 361.

[8] Kuo, W. S., Lie, Y. M., Hsieh, Y. Y., and Lin, T. F., 2005, "Condensation heat transfer and pressure drop of refrigerant R-410A flow in a vertical plate heat exchanger," International Journal of Heat and Mass Transfer, 48(2526), pp. $5205-5220$.

[9] Hsieh, Y. Y., and Lin, T. F., 2002, "Saturated flow boiling heat transfer and pressure drop of refrigerant R-410A in a vertical plate heat exchanger," International Journal of Heat and Mass Transfer, 45(5), pp. 1033-1044.

[10] Quoilin, S., Orosz, M., Hemond, H., and Lemort, V., 2011, "Performance and design optimization of a low-cost solar organic Rankine cycle for remote power generation," Solar Energy, 85(5), pp. 955-966.

[11] Quoilin, S., 2011, "Sustainable Energy Conversion Through the Use of Organic Rankine Cycles for Waste Heat Recovery and Solar Applications," Ph.D. thesis, University of Liege, Liege.

[12] European standard European Standards (1999), Refrigerant compressors - Rating conditions, tolerances and presentation of manufacturer's performance data, DIN EN 12900.

[13] http://www.emersonclimate.com/en-S/Pages/default.aspx

[14] Lemort, V., Quoilin, S., Cuevas, C., and Lebrun, J., 2009, "Testing and modeling a scroll expander integrated into an Organic Rankine Cycle," Applied Thermal Engineering, 29(14-15), pp. 3094-3102.

[15] Lemort, V., Declaye, S., and Quoilin, S., 2011, "Experimental characterization of a hermetic scroll expander for use in a micro-scale Rankine cycle", Journal of Power and Energy, 0(0) pp. 1-10.

[16] Lemort,V., 2008, "Contribution to the characterization of Scroll machine in compressor and expander modes," $\mathrm{PhD}$. Thesis, University of Liege, Liege.

[17] Thermal losses of heat storage, http://herve.silve.pagesperso-orange.fr/bilan_th.htm

[18] Quoilin, S., Declaye, S., Tchanche, B.F., Lemort, V., 2011, "Thermo-economic optimization of waste heat recovery Organic Rankine Cycles," Applied Thermal Engineering, 31, pp. 2885-2893.

[19] http://solarelectricityhandbook.com/solar-irradiance.html

[20] http://www.evworks.com.au/store/datasheets/SAGInoMI YA\%204-way\%20reversing\%20valves.pdf

[21] Kinab, E., Marchio, D., Rivière, P., Zoughaib, A., 2010, "Reversible heat pump model for seasonal performance optimization," Energy and Buildings, 42, pp. 2269-2280. 